\title{
Hydro-mechanical behaviour of alkali-activated binder treated soil
}

\author{
Enza Vitale $^{1, *}$, Antonello Marocco ${ }^{1}$, Michael $\mathrm{Khatib}^{2}$, and Giacomo Russo ${ }^{3}$ \\ ${ }^{1}$ Department of Civil and Mechanical Engineering, University of Cassino and Southern Lazio, Italy \\ ${ }^{2}$ Ginger - CEBTP, Elancourt, France \\ ${ }^{3}$ Department of Earth Science, Environment and Resources, University of Napoli Federico II, Italy
}

\begin{abstract}
An experimental investigation on the mechanical improvement induced by alkali-activated binder based on the activation of a fluidal bed combustion fly ash on a clayey soil has been developed. The use of these binders for geotechnical applications is a promising issue in terms of sustainability since it reduces the carbon footprint and allows reusing secondary by-products such as artificial pozzolans. Treated samples were prepared by mixing soil and fly ash with water and alkaline solution and dynamically compacted. Mechanical behaviour has been investigated by means of triaxial tests performed on treated samples compacted at optimum water content. Addition of alkali activated binder increased stiffness and shear strength of treated samples, whose extent depends on binder content and curing time. Macroscopic behaviour of treated soil has been linked to the experimental evidences at microscale. Microstructural analyses highlighted a high reactivity of alkali-activated fly ashes as alumino-silicate source promoting the precipitation of new mineralogical phases with cementitious properties. Amorphous alumino-silicate gels produced from alkali-activation of fly ash bound particles aggregates leading to a decrease of cumulative pore volume and porosity of treated samples and modification of the modal pore size.
\end{abstract}

\section{Introduction}

The development and the use of environmentally friendly binders as an alternative solution to traditional binders such as lime or cement in a low carbon agenda is of prime importance particularly in the construction sector, for which cement production contributes to at least $5-8 \%$ of global carbon dioxide. The use of novel binders for geotechnical applications is a promising issue in terms of sustainability since it reduces the carbon footprint and allows reusing secondary by-products such as artificial pozzolans. These by-products can be involved in soil improvement as cementing agents if properly activated, inducing a mechanical improvement of natural soils, not suitable for construction purposes. Alkali activated binders represent a viable alternative to the use of ordinary stabilizing agents for soil improvement [1]. Differently from the use of lime and cement for soil improvement [2-8], experimental research about the use of alkali activated binders in soil improvement is still limited; nevertheless, recent studies highlight the relevant potential of novel binders for geotechnical purposes. Cristelo et al. (2012) [9] researched the optimum fly ash - based alkaline activated binder for the improvement of soil to be used in rammed earth construction through a parametric analysis using laboratory tests. Rios et al. (2016) [10] compared the mechanical behaviour of samples of sand improved by an alkali activated fly ash binder and the similar samples improved by cement, highlighting the effectiveness of the alkali activated binders in increasing the shear strength properties of the soil on the long term even then the effectiveness can be considered as a promising technique of as widely used in practice with lime and/or cement stabilisation.

Alkali activation of by-products is the consequence of a chemical reaction between of an aluminosilicate source with an alkaline solution (i.e. sodium hydroxide, sodium silicate). The aluminosilicate source is formed by precursor materials like natural pozzolan (e.g., pyroclastic soils), or artificial pozzolans (e.g., fly ash, silica fume, steel sludge). The chemo-physical evolution occurring after the activation promotes the formation of cementitious compounds [11-13]. The reaction mechanism is promoted by the alkaline solution, which enables the dissolution of the aluminosilicate source (precursor) and the subsequent precipitation of gel phases which condense in a three-dimensional aluminosilicate network [14-17].

In the present study, an experimental investigation on the mechanical improvement induced by alkali-activated binder based on the activation of a fluidal bed combustion fly ash on a clayey soil has been developed. Microstructural features and mechanical behaviour have been investigated by means of MIP and triaxial tests performed on treated samples compacted at optimum water content. The effects of binder content and curing time on mechanical performance of treated samples have

Corresponding author: e.vitale@unicas.it 
been considered. Mineralogical changes induced by alkali-activated binder have been monitored over time by means of X ray diffraction (XRD), Scanning Electron Microscopy (SEM) and Energy Dispersive Spectroscopy (EDS) analyses.

\section{Material and experimental procedures}

\subsection{Material}

The artificial pozzolan used in the present work is a fluidal bed combustion fly ash supplied by a power plant located in Italy. Raw material is composed by vitreous and crystalline phases which include calcium-containing minerals: anhydrite, calcite and other minerals: quartz and hematite. The chemical composition of fly ash is reported in Table 1. The sodium silicate solution was supplied by Woellner (Germany) with a $\mathrm{SiO}_{2} / \mathrm{Na}_{2} \mathrm{O}$ mass ratio of 1.7. Speswhite kaolin from deposits in the South West of England was the soil considered for the experimental investigation. The specific gravity $\mathrm{G}_{\mathrm{s}}$ is 2.6 and its surface area, determined by BET, is $14 \mathrm{~m}^{2} / \mathrm{g}$. The $\mathrm{pH}$ value is 4.6 and plastic limit and liquid limit are respectively $32 \%$ and $70 \%$, with a plasticity index IP equal to $38 \%$. The soil is manly composed of kaolinite clay minerals with small amounts of quartz and muscovite. The chemical composition of the soil is given in Table 2.

Table 1. Chemical composition of fly ash.

\begin{tabular}{|c|c|}
\hline Constituent & Percentage (\%) \\
\hline $\mathrm{SiO}_{2}$ & 39.4 \\
\hline $\mathrm{Al}_{2} \mathrm{O}_{3}$ & 19.8 \\
\hline $\mathrm{CaO}$ & 5.2 \\
\hline $\mathrm{K}_{2} \mathrm{O}$ & 1.8 \\
\hline $\mathrm{Fe}_{2} \mathrm{O}_{3}$ & 7.14 \\
\hline
\end{tabular}

Table 2. Chemical composition of Speswhite kaolin.

\begin{tabular}{|c|c|}
\hline Constituent & Percentage (\%) \\
\hline $\mathrm{SiO}_{2}$ & 53.80 \\
\hline $\mathrm{Al}_{2} \mathrm{O}_{3}$ & 43.75 \\
\hline $\mathrm{CaO}$ & 0.02 \\
\hline $\mathrm{K}_{2} \mathrm{O}$ & 1.45 \\
\hline $\mathrm{TiO}_{2}$ & 0.05 \\
\hline
\end{tabular}

\subsection{Samples preparation}

Soil samples treated with alkali-activated binder (KAFA) were prepared by considering increasing fly ash percentages equal to $10 \%$ (sample KFA10\%) and $20 \%$ (sample KFA20\%) by dry weight of solids (soil+ fly ash) and alkaline solution /fly ash mass ratio equal to 0.5 . The selected percentage of alkali-activated fly ashes are comparable with the amounts of cement generally used for soil treatment. Compaction characteristics of not treated sample and alkali-activated fly ash treated samples (KA-FA) were determined according to ASTM D698-91 using a Standard Proctor test. With reference to compaction curves, optimum initial moisture content $\left(\mathrm{w}_{\mathrm{opt}}=30 \%\right.$ for not treated kaolin, $\mathrm{w}_{\mathrm{opt}}=29 \%$ for $\mathrm{KA}$ FA10\% treated soil and $\mathrm{w}_{\mathrm{opt}}=27,3 \%$ for KA-FA20\% treated soil) was selected for both not treated and treated samples. Treated samples were then sealed in plastic bags and cured at increasing curing times of $24 \mathrm{~h}, 10$ days and 28 days before performing mineralogical, microstructural and mechanical tests.

\section{$2.3 \mathrm{X}$ ray diffraction analysis (XRD)}

Mineralogical composition of samples was investigated by X-ray analysis performed on randomly oriented powder using a Brucker AXS D8 Advance Diffractometer with $\mathrm{CuK} \alpha(\lambda=0.154 \mathrm{~nm})$ radiation and a step size of $0.021^{\circ}$. Samples were dehydrated before testing by freeze-drying technique.

\subsection{Mercury intrusion porosimetry (MIP)}

MIP tests were performed by a double chamber Micromeritics Autopore III apparatus. In the filling apparatus (dilatometer) samples were outgassed under vacuum and then filled by mercury allowing the increase of absolute pressure up to the ambient one. Using the same unit, the intrusion pressure was than raised up to ap-proximately $200 \mathrm{kPa}$ by means of compressed air. The detected entrance pore diameters range between 134 $\mu \mathrm{m}$ and $7.3 \mu \mathrm{m}$ (approximately $0.01 \mathrm{MPa}-0.2 \mathrm{MPa}$ for a mercury contact angle of $139^{\circ}$ ). After depressurisation to ambient pressure, samples were transferred to highpressure unit, where mercury pressure was in-creased up to $205 \mathrm{MPa}$ following a previously set intrusion program. MIP tests were performed on alkali-activated fly ash treated samples at different binder contents (KAFA10\% and KA-FA20\%) and curing times (namely $24 \mathrm{~h}$ and 28 days).

\subsection{SEM/EDS Analyses}

Surface state modifications and microstructural features of treated samples have been examined through Scanning Electron Microscopy by using JEOL JSM 840A microscope. EDS Analyses have been performed to determine the elemental composition of selected areas of the samples. Treated samples have been dehydrated by freeze-drying technique. A pre-treatment gold coating has been applied for SEM observations.

\subsection{Triaxial tests}

Drained triaxial compression tests have been performed on saturated samples by means of a controlled stresspath triaxial cell [18]. Saturated samples have been isotropically compressed at mean effective stress of $50 \mathrm{kPa}$. Deviatoric stages in drained conditions have been then 
performed at deformation rate of $0.5 \% / \mathrm{h}$ up to failure. Treated samples have been tested at increasing curing times (namely 10 days and 28 days) and increasing binder contents (i.e. KA-FA10\% and KA-FA20\%).

\section{Results}

Results of triaxial drained compression tests on raw kaolin and alkali activated binder treated samples (KAFA10\%) at increasing curing times, namely 10 days and 28 days, are reported in Figure 1. A ductile and contractile behaviour is observed for kaolin, whereas treated samples exhibit an overall increase of stiffness and shear strength. Effects of binder content on mechanical response of treated samples are highlighted by stress-strain curves after 28 days of curing reported in Figure 2. As shown in Figure 2, increasing binder content results in a progressive increase of stiffness and shear strength, coupled with a dilative behaviour upon shearing. The improvement of the mechanical behaviour of treated sample is due to bonding effects induced by precipitation of gel phases resulting from development of alkaline activation process. Treated samples showed a stress-strain curve typical of cemented materials [10, 19], with a peak stress attained at low strain levels, followed by an abrupt strain softening due to bonds degradation. Microstructural features of samples treated with alkali-activated fly ash compacted at optimum water content have been investigated by means of MIP. MIP results on $10 \%$ alkali-activated fly ash treated samples (KA-FA10\%) as function of curing time are shown in Figure 3. Cumulative intruded void ratio decreases as curing time increases, highlighting a gradual overall reduction of porosity over time (Fig. 3a). Pore size distribution showed a decrease of frequency of main pore entrance diameters and an increase of frequency of pores entrance diameters in the small range (between $0.008 \mu \mathrm{m}-0.06 \mu \mathrm{m}$ ). Modal pore size is shifted towards smaller sizes as a consequence of formation of a well-connected network of gel hydrates over time, which increases small pores frequency and contributes to the progressive decrease of main pore entrance. Frequency of larger pores (i.e. pore entrance diameter $0.5 \mu \mathrm{m}-300 \mu \mathrm{m}$ ) is not affected by curing condition. Cumulative intruded void ratios and pore size distributions of samples treated with $10 \%$ and $20 \%$ of binder (KA-FA10\% and KA-FA20\%) after 28d days of curing are shown in Figure 4. A decrease of cumulative intruded void ratio is observed as the binder content increases, which is consistent with a reduction of porosity of the sample. Addition of alkali-activated fly ash modifies the modal pore size of treated samples and the frequency of pores in the small diameters. A decrease of frequency in the largest pore range (i.e. entrance pore diameter $>0.5 \mu \mathrm{m}$ ) is observed for higher binder content. The change of microstructural features due to alkaline activation were also observed by SEM analysis. SEM observations of KA-FA10\% treated compacted samples after $24 \mathrm{~h}$ and 28 days of curing are reported in Figure 5. SEM images clearly show particles morphology, as well as aggregated fabric induced by compaction. At low magnifications, no relevant differences in term of microstructure are detected for $24 \mathrm{~h}$ and 28 days cured samples (Fig. 5a, 5d). A coating of gel phases on the surface of particles aggregates is observed at higher magnifications after 28 days of curing (Fig. 5b, 4e). As observed is consistent with the reduction of porosity and the increase of pores frequency in the small diameter range detected by MIP results.
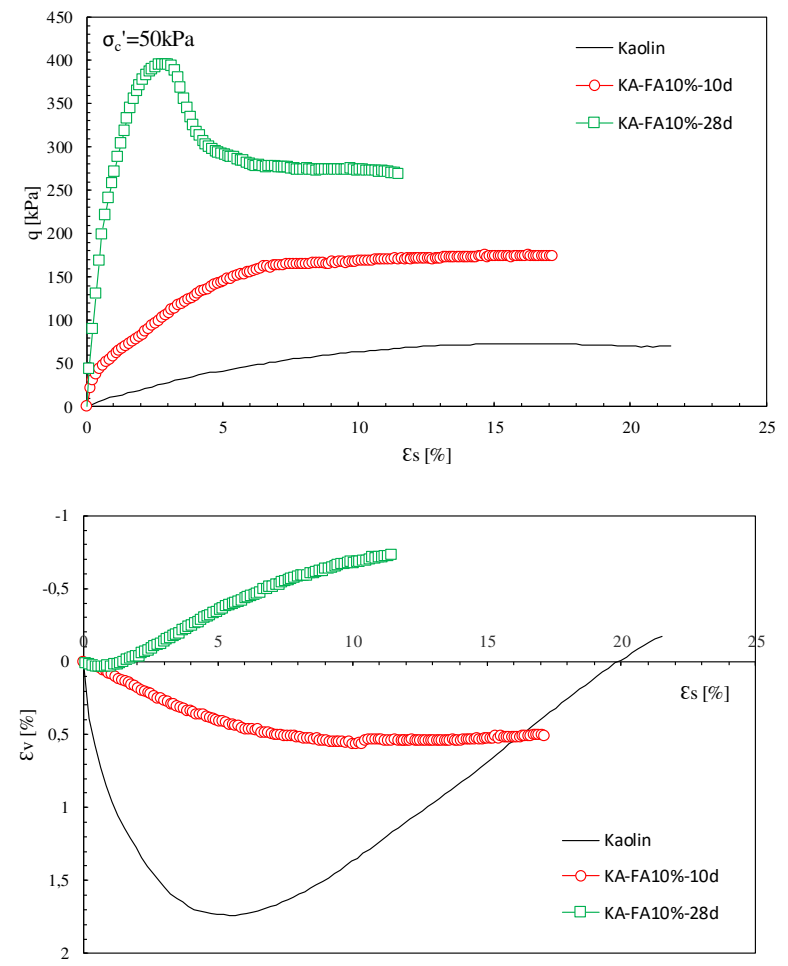

Fig. 1. Triaxial test results: stress-strain curves of raw and $10 \%$ treated samples (KA-FA10\%) at increasing curing time.
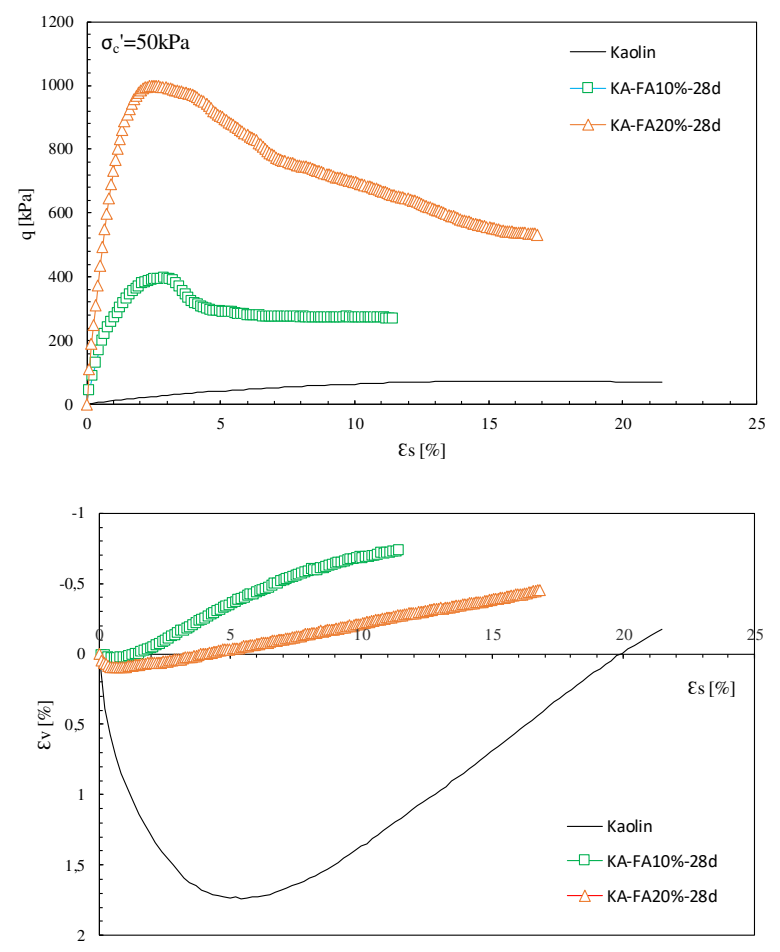

Fig. 2. Triaxial test results: stress-strain curves of raw and binder treated samples at 28 days of curing. 

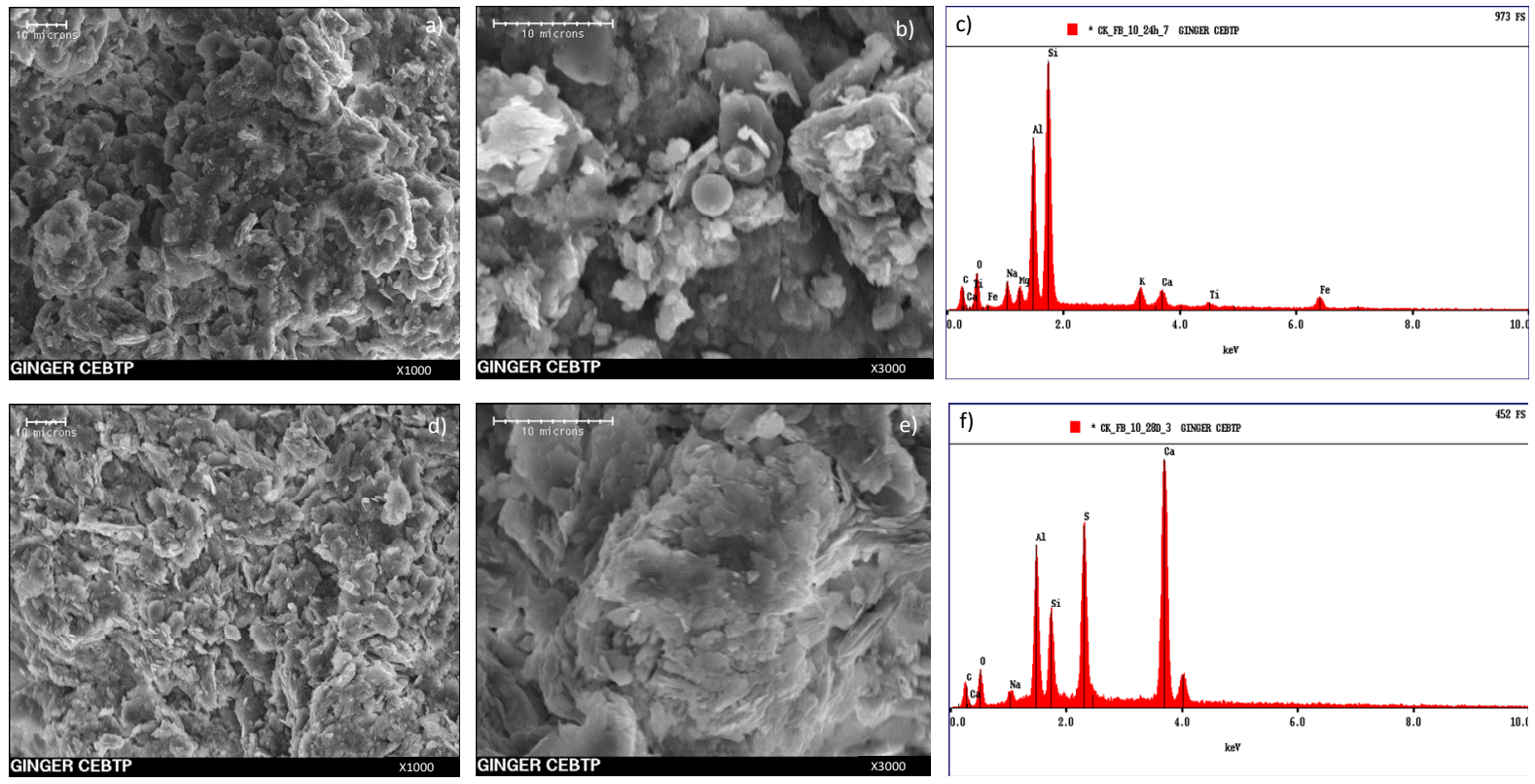

Fig. 5. 10\% alkali-activated fly ash treated samples (KA-FA10\%): a), b) SEM observations after 24h of curing; c) EDS spectrum after 24h of curing; d), e) SEM observations after 28 days of curing; c) EDS spectrum after 28 days of curing.

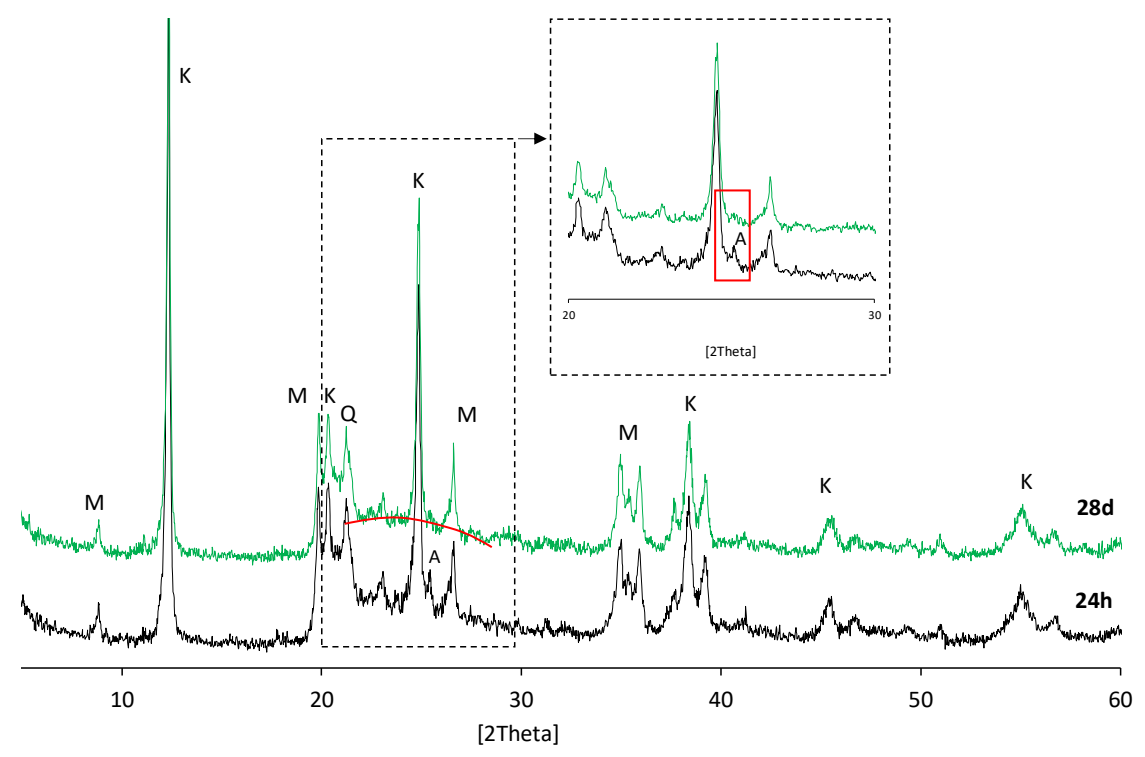

Fig. 6. X Ray diffraction patterns of $10 \%$ alkali activated fly ash treated sample (KA-FA10\%) at increasing curing time: M= muscovite, $\mathrm{K}=$ kaolinite, $\mathrm{Q}=$ quartz, $\mathrm{A}=$ anhydrite

Mineralogical composition of treated sample is modified by alkaline activation process. X Ray diffraction patterns of samples treated with $10 \%$ of alkali activated fly ash binder (KA-FA10\%) after $24 \mathrm{~h}$ and 28 days of curing are shown in Figure 6. Dissolution of crystalline phases such as anhydrite $\left(\mathrm{CaSO}_{4}\right)$ is evidenced by disappearance of its characteristic peaks after 28 days of curing. A broad reflection between $25^{\circ}$ and $35^{\circ}$ corresponding to new poorly crystalline compounds resulting from alkaline- activation reactions was observed in the treated samples after 28 days of curing. Chemo-mineralogical evolution of the system is also confirmed also by EDS analysis which evidences, for the 28 days cured sample, the presence of peaks of sulphate and calcium in the system released from anhydrite dissolution and a reduction of silicon and aluminum peaks as a result of formation of alkaline alumina-silicate gel (Fig. 5f). 

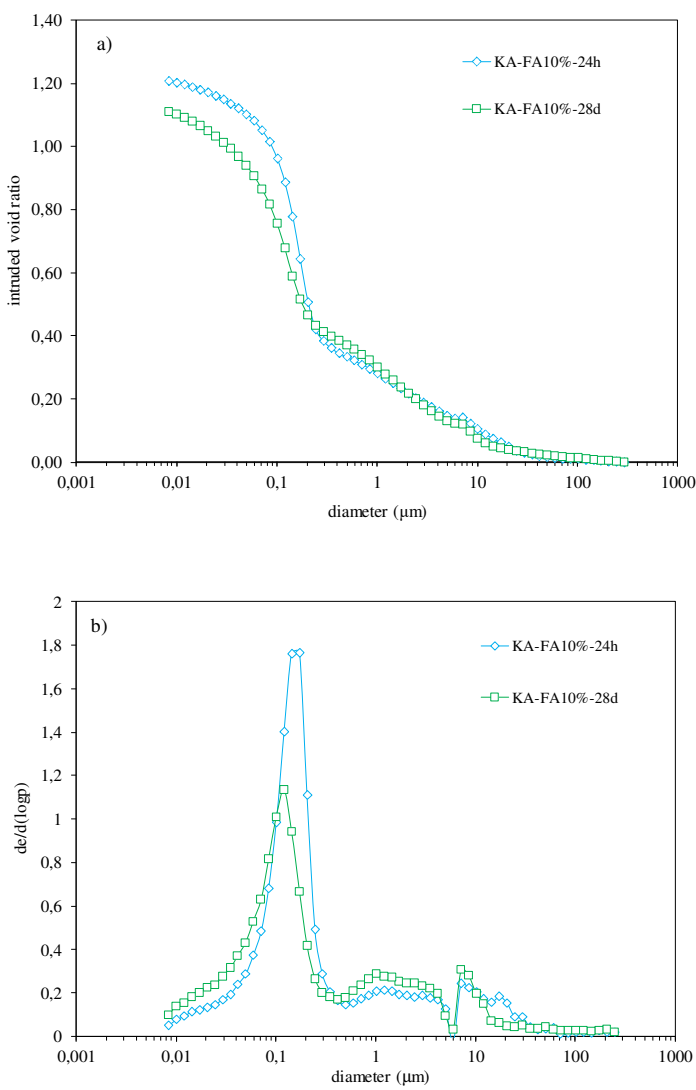

Fig. 3. a) Cumulative intruded volumes and b) Pore size distributions of samples treated with $20 \%$ of binder at increasing curing time.
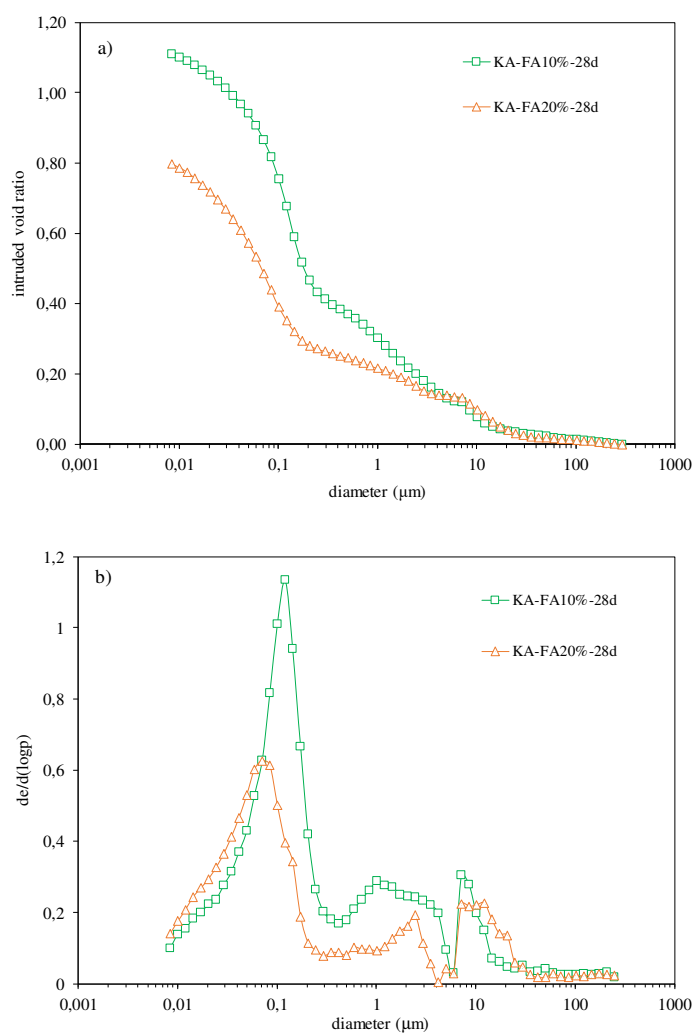

Fig. 4. a) Cumulative intruded volumes and b) Pore size distributions of samples treated with $10 \%$ and $20 \%$ of binder at $24 \mathrm{~h}$ of curing.

\section{Conclusions}

An insight into the mechanical improvement induced by alkali-activated binders on a clayey soil has been presented. Triaxial tests performed on treated sample highlighted the effectiveness of alkali activated binders to promote an improvement of the mechanical behaviour of treated soil. An increase of stiffness and shear strength was observed since the very short term, whose extent depends on curing time and binder content. The macroscopic behaviour of treated soil has been linked to the experimental evidences at microscale level. Amorphous alumino-silicate gel produced from alkaliactivation of fly ash binds particles aggregates leading to a decrease of cumulative pore volume and porosities of treated samples. Chemo-mineralogical analyses confirm the high reactivity of the alkali activated fly ash as alumino-silicate source promoting the dissolution of fly ash particles and progressive precipitation of new mineralogical phases with cementitious properties.

\section{Acknowledgements}

The project has received funding from the European Union's Horizon 2020 research and innovation programme under the Marie Sklodowska-Curie grant agreement No 778120.

\section{References}

1. A. Wilkinson, A. Haque, J. Kodikara, Proc Inst Civ Eng - Ground Improv. 163, 3 (2010)

2. E. Vitale, D. Deneele, G. Russo, G. Ouvrard, Appl. Clay Sci. 132, pp. 223-231 (2016)

3. E. Vitale, M. Cecconi, P. Croce, D. Deneele, V. Pane, G. Russo, A. Vecchietti, CNRIG 2016 Procedia Engineering 158, pp. 81 - 86 (2016)

4. E. Vitale, D. Deneele, M. Paris, G. Russo, Appl. Clay Sci. 141, pp. 36-45 (2017)

5. G. Guidobaldi, C. Cambi, M. Cecconi, D. Deneele, M. Paris, G. Russo, E. Vitale, Eng. Geol. 221, pp. 193-201 (2017)

6. G. Guidobaldi, C. Cambi, M. Cecconi, P. Comodi, D. Deneele, M. Paris, G. Russo, E. Vitale, A. Zucchini, Eng. Geol. 245, pp. 333-343 (2018)

7. E. Vitale, D. Deneele, G. Russo, D. De Sarno, M. V. Nicotera, R. Papa, G. Urciuoli, Acta Geotech. https://doi.org/10.1007/s11440-019-00797-8 (2019)

8. D. De Sarno, E. Vitale, D. Deneele, M. V. Nicotera, R. Papa, G. Russo, G. Urciuoli, E3S Web of Conferences 92, 11006 (2019)

9. N. Cristelo, S. Glendinning, A.T. Pinto, Ground improvement 164, pp.73-82 (2011)

10. S. Rios, N. Cristelo, A. V. da Fonseca, C. Ferreira, J. Mater. Civ. Eng. 28, 2 (2016)

11. J. Davidovits, J Therm Anal 37, pp. 1633-1656 (1991)

12. H. Xu, J.S.J. van Deventer, Int J Miner Process 59, pp. 247-266 (2000) 
13. E. Coudert, M. Paris, D. Deneele, G. Russo, A. Tarantino, Construction and Building Materials 201, pp. 539-552 (2019)

14. P. Duxon, A. Fernàndez-Jiménez, J. L. Provis, G. C. Lukey, A. Palomo, J. S. J, van Deventer, Journal of Materials Science 42, 9 (2007)

15. P. Sargent, P. N. Hughes, M. Rouainia, M. L. White Eng Geol. 152, 1 (2013)

16. E. Vitale, G. Russo, D. Deneele, E3S Web of Conferences 92, 11003 (2019)

17. E. Vitale, G. Russo, D. Deneele, Geotechnical Research for Land Protection and Development. CNRIG 2019. Lecture Notes in Civil Engineering, vol 40. Springer, Cham (2020)

18. S. Aversa, F. Vinale, ASTM Geot. Test. Journ., 18 (1), pp. 116-120 (1995)

19. S. Rios, A.V. da Fonseca, B. Baudet, Acta Geotechnica 9 (2), pp. 215-226 (2014) 